\title{
Preffered Methods of Treating Obesity in Late Adulthood and Senior Age
}

J. Babecka (Jozef Babecka)', M. Popovicova (Maria Popovicova)², M. Belovicova

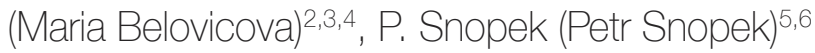

${ }^{1}$ Catholic University in Ruzomberok, Faculty of Health, Ruzomberok, SK.

${ }^{2,3}$ St. Elizabeth University of Health and Social Sciences, Bratislava, SK.

${ }^{3}$ Internal Clinic for Liver Disease Diagnosis and Treatment, Remedium s. r. o., SK.

${ }^{4}$ Slovak Society of Practical Obesitology (SSPO), Bardejov, SK.

${ }^{5}$ Tomas Bata University in Zlin, Faculty of Humanities, Department of Health Care Sciences, Zlin, CZ.

${ }^{6}$ Hospital in Zlin, Zlin, CR.

\section{E-mail address:}

jozef.babecka@ku.sk

\section{Reprint address:}

Jozef Babecka

Catholic University in Ruzomberok

Faculty of Health

Ruzomberok

Slovakia

Source: Clinical Social Work and Health Intervention

Volume: 12

Issue: 5

Pages: $47-54$

Cited references: 15

\section{Reviewers:}

Selvaraj Subramaniam

Kuala Lumpur

Roberto Cauda

Institute of Infectious Diseases, Catholic University of the Sacred Heart, Rome, IT

\section{Keywords:}

Old Age. Aging. Obesity. Metabolic Syndrome.

\section{Publisher:}

International Society of Applied Preventive Medicine i-gap

CSWHI 2021; 12(5): 47 - 54; DOI: 10.22359/cswhi_12_5_07 (C) Clinical Social Work and Health Intervention

\section{Abstract:}

Objective: To identify preferred solutions - therapy - for overweight and obesity in older adults and seniors

Participants: A total of 110 respondents were contacted, out of which 14 refused to cooperate or filled in the questionnaire incorrectly. The return of questionnaires was 96 , i.e. $100 \%$. The group of respondents consisted of individuals of both sexes, aged 50 and over, living in a natural social environment or in one of the selected institutions. Due to the fact that - in our opinion - a relatively large amount of attention is paid to the senior age group 
while the group of people in the age range of 50-64 is forgotten, we have not chosen the senior age respondents exclusively.

Methods: The data obtained by the processing of the questionnaires were analytically evaluated. For statistical processing a program StatisticaCz version 9 was chosen, a descriptive analysis of the data was performed, followed by analysis by comparing averages and particular tests of statistical significance (Chi-square test, Kruskal Wallis, KendalovoTau).

Results: An adjustment of the diet as a part of the solution of the overweight and obesity therapy would be chosen by the most respondents, $75(46.5 \%)$ of them. $44(27.0 \%)$ respondents would choose sport or other physical activity. 11 (6.7\%) respondents would deal with overweight and obesity pharmacologically - with the help of medications, and only $25(15.3 \%)$ respondents would choose surgery as a way of dealing with overweight and obesity. On the contrary, only $8(4.9 \%)$ respondents were not interested in dealing with the weight gain. $24(25.0 \%)$ respondents would choose the surgical way of solving obesity. Ananswer"possibly yes"was chosen by13 (13.5\%) respondents. 21 (21.9\%) individuals inclined to the "rather not" variant. 33 (34.4\%) respondents chose the "certainly not"answer. An answer"I don't know" was chosen by $5(5.2 \%)$ respondents.

Conclusion: Obesity is a global social problem which is not to be solved just in healthcare and it is certainly not an issue of an individual.

\section{Introduction}

BMI of $30 \mathrm{~kg} / \mathrm{m}^{2}$ and more is considered obesity. However, this criterion has certain shortcomings, especially in old age. There may be problems with weighing and measuring height in immobile patients. Other problems can arise as a result of old-age changes in one's body. The biggest disadvantage of BMI is that it does not reflect changes in body composition. When assessing using BMI, the altered muscle-to-fat ratio underestimates obesity, while on the other hand the decrease in height during aging overestimates it (1). Alternative measurements (arm-span, knee height) were developed to determine the height of bedridden patients, but their contribution was not adequately validated. BMI increases as we age. Its increase is more significant when evaluated using longitudinal studies. BMI is not considered a very accurate tool for assessing nutritional status, as it only has $50-60 \%$ sensitivity in detecting obesity and malnutrition.

\section{Waist circumference}

Large waist circumference (more than $102 \mathrm{~cm}$ in men and more than $88 \mathrm{~cm}$ in women) is more common in men over the age of 65 than in younger age groups (2). The incidence of obesity assessed by waist circumference is greater than that assessed by BMI.The waist circumference is an indicator of the amount of intra-abdominal fat whichproduces the substances causing the metabolic syndrome. Waist circumference is a better indicator of ischemic heart disease than BMI. Larger waist circumference is associated with worse prognosis even in people with lower BMI (2).

\section{Aging changes in the body}

Aging changes in the body significantly modify theassessment of nutritional status in older age. Between the age of 20 and 30, the progressive loss of lean body mass begins. Between the age of 20 and 70, muscle mass is reduced by $40 \%$ and the amount of fat increases. The amount of fat is greatest between the age of 60 and 70. After the age of 70, the reduction in fat-free mass continues and the amount of fat also begins to decrease. During aging, fat is redistributed. The amount of intra-abdominal fat increases relatively more as a result of greater loss of limb 
muscle and infiltration offat into the liver. Fatty liver and musclesimpair the effectiveness of insulin (3). An increase in abdominal fat slows down with age. Muscle atrophy contributes to weight loss in an older age, and thus the proportion of fat in the composition of the body increases even with weight loss (1).

\section{Practical problems in assessing the state of nutrition in old-age patients}

Many older people are not able to stand up, so their height and weight cannot be measured. A presence of edemarestrains the determination of BMI. Measuring the waist circumference is impossible in bedridden patients. When measuring the waist circumference, it is necessary to maintain all the requirements for correct assessment. The examined person should stand upright with the weight evenly distributed between both legs, which are $10-15 \mathrm{~cm}$ apart. The measurement should be taken in the morning on an empty stomach, at the end of normal expiration. The patient must not draw in the abdomen and should not be meteoristic. The measuring tape must not be elastic and must be applied loosely, parallel to the floor, at half the distance between the edge of the lowest palpable rib and the spinailiacasuperior. The hips circumference is measured at the widest part. Evaluation of obesity using the ratio of hip and waist circumference in old age patients is affected by atrophy of the gluteal muscles. An open question is the determination of the ideal weight. There are several ideal weight calculators on the Internet, but none of them is validated for patients of older age. Between the age of 70 and 75 , overweight people (BMI $25.6 \mathrm{~kg} / \mathrm{m} 2$ ) have the best prognosis (4). Due to this fact, it is not recommended to use the same BMI categories as in younger age groups in people over 70 years of age. The same is true of waist circumference, as there has been lower mortality in men with larger waist circumferences (5). The usual weight (i.e. the weight a person has had for a long time) is used to assess weight loss or gain.

\section{Treatment of obesity}

The "Primumestnonnocere" also applies to the treatment of obesity, especially in old age. Before starting, it is necessary to consider whether this treatment is feasible and to assess its benefits and risks (whether the patient will live long enough to see its effect). Obesity in the elderly is usually a long-term issue, so the changes caused by obesity are advanced and less reversible. In addition, changing eating habits is very difficult. Older people have a reduced ability to adapt food intake to current needs (6). Reducing the amount of food and eliminating some ingredients has a negative impact on quality of life and can cause a deficiency of vitamins and minerals. The choice of diet is influenced by diseases (for example, a high-protein diet is contraindicated in kidney disease). An adverse effect of weight reduction is muscle loss. In a meta-analysis of 52 studies looking at the impact of energy restriction, it was found that in half of the studies, the reduction in lean body mass contributed to weight loss in $25 \%$ or more. If exercise was also part of the program, the loss of lean body mass was only $11 \%$. A cautious approach is particularly required when obesity is combined with sarcopenia (sarcopenic obesity), which increases the overall mortality by $24 \%$. Weight reduction and exercise also alleviate the symptoms of fragility. Weight loss is associated with loss of femur bone density, but not of the spine nor of other bones. A $10 \%$ weight reduction is associated with a significant increase in the risk of hip fracture. When reducing weight, it is most important that the daily energy intake of food is at least $500 \mathrm{kcal}(2,092 \mathrm{~kJ})$ less than the expenditure. At this value, a weight reduction of $0.5-0.7 \mathrm{~kg} /$ week can be expected. The required amount of energy is calculated by multiplying basal metabolism by a coefficient depending on physical activity. There are several calculators for calculating basal metabolism available on the Internet (7). In general, the daily energy expenditure in older age is $30-35 \mathrm{kcal} / \mathrm{kg}$, depending on the activity. The tolerance of reduced food intake will be improved by drinking water before meals, slow eating and a diet with stronger satiating effect. The composition of the diet is important. There is a large number of reduction diets. Some of them can also be harmful (for example, a highfat diet). In old age, the use of very lowenergy diets is not recommended. They should contain a sufficient amount of quality proteins, vitamins and minerals. Many of these requirements are met in a high-protein diet. A high protein diet is considered a diet with a protein content of more than $0,8 \mathrm{~g} / \mathrm{kg} /$ day, or if the protein accounts for more than $15-16 \%$ of energy (8). A high-protein diet in- 
creases the secretion of neuropeptides, cholecystokinin and peptideYY, which induce satiety and reduce orexigenic ghrelin production. High protein content is associated with a high satiating effect, which improves compliance. Another advantage is that proteins have the greatest thermic effect. Their processing consumes $15-30 \%$ of the energy they contain. The authors (8) state that in polysaccharides it is $5-10 \%$. Fats have the lowest thermic effect $(0-3 \%)$.A diet with a higher protein content is also advantageous in older age as the use of proteins in old age is worsened. A recommended daily dose of protein in the elderly is higher ( $1 \mathrm{~g} / \mathrm{kg}$ body weight). In patients with weak muscles, this dose is $1-1.6 \mathrm{~g} / \mathrm{kg} /$ day. Higher protein intake has a protective effect on muscles.Another advantage of a high-protein diet is a $50 \%$ reduction in weight gain after the reduction diet (8). Depending on the source of the protein, a high-protein diet may increase the risk of kidney stones. Animal products high in protein often contain large amounts of cholesterol and triglycerides, which can have negative effects.Other sources of protein are more suitable, such as fish, soy and other legumes. High protein intake can increase phosphate and sulphate production. Therefore, a sufficient intake of vegetables and fruits that have an alkalizing effect is recommended. Monitoring of renal function is also recommended. Excess amino acids can be transformed into glucose and fats, causing weight gain.A high protein diet is not suitable for patients with advanced kidney disease. Pharmacological treatment of obesity is not currently recommended in elderly patients, with the exception of antidepressants in the treatment of night eating (Waldan's syndrome), in which the patient has early anorexia and consumes at least $1 / 4$ of food at night (9).

\section{Surgical treatment}

For some patients, due to a failure of the conservative treatment, a surgical treatment may be considered. Criteria for bariatric surgery include a BMI of 40 or $35-40 \mathrm{~kg} / \mathrm{m} 2$, with other complications that can be ameliorated by surgery (e.g., nocturnal apnea, diabetes mellitus, and resistant hypertension, impaired mobility) (1). Number of patients with surgically treated obesity is also increasing in senior age. In the United States, people aged 60 years make up $10 \%$ of pa- tients operated on for obesity. A meta-analysis of 26 studies with 8,149 patients aged 55 years and older found improved level of diabetes compensation in $54.3 \%$ and better control of hypertension in $42.5 \%$. Dyslipidemia improved in $42.5 \%$ of patients. $53.7 \%$ of patients lost the extra weight. Complications occurred in $14.7 \%$ of patients.Mortality within 30 days after surgery was $0.01 \%(10)$.

\section{Conclusion}

Several negative effects of obesity persist into old age, but many are milder. Negative consequences correlate more with waist circumference than with BMI. Overweight people have the best prognosis (BMI $25-30 \mathrm{~kg} / \mathrm{m} 2$ ). The treatment of obesity in old age should be carefully considered, as its effect is less significant in old age and higher body weight may have a protective effect in some diseases. Measures formuscle maintenance (adequate protein intake and exercise) are also part of the obesity treatment.

\section{Research sample group and methodology}

A total of 110 respondents were contacted, out of which 14 refused to cooperate or filled in the questionnaire incorrectly. The return of questionnaires was 96 , i.e. $100 \%$. The group of respondents consisted of individuals of both sexes aged 50 and over, living in a natural social environment or in one of the selected institutions. Due to the fact that - in our opinion - a relatively large amount of attention is paid to the senior age group while the group of people in the age range of 50-64 is forgotten, we have not chosen the senior age respondents exclusively. According to the WHO, those people do not yet belong to the category of seniors, but they are part of the population that is already preparing for the senior age. The data obtained by the processing of the questionnaires were analytically evaluated. For statistical processing a program StatisticaCz version 9 was chosen, a descriptive analysis of the data was performed, followed by analysis by comparing averages and particular tests of statistical significance (Chi-square test, Kruskal Wallis, KendalovoTau).

Objective: To identify preferred solutions therapy - for overweight and obesity in older adults and seniors 


\section{Hypotheses}

HO We assume that there will be no significant difference between the preferred ways of dealing with overweight and obesity between men and women.

Ha We assume that there will be a significant difference between the preferred ways of dealing with overweight and obesity between men and women.

\section{Analysis of results}

Out of the total number of 96 respondents, 27 $(28.1 \%)$ respondents were in the category under 59 years of age, 69 (71.9\%)respondents were over 60 years of age. The average age of the respondents was 64.25 years. The youngest respondent was 50 years old at the time of the research, the oldest respondent was 85 years old. The most numerous group consisted of respondents in the age category of 63 to 65 years, i.e. the senior sphere. The second most numerous groupwere older people aged 58 years and another large group was again the senior category aged 70 to 72 years. Of this, according to gender, $61(63.5 \%)$ were women and $35(36.5 \%)$ were men. Below is a table based on age, weight, height and BMI.

Table 2 shows that the significance level of 0.05 is less than the significance of $p$ in all tests performed. Thus, it can be claimed that no statistically significant difference was found in the choice of options for treating overweight and obesity between men and women. Based on statistical testing, no significant difference was found between the selected options for dealing with overweight and obesity depending on the age of the respondents. In this case, thanks to the Chi-square reciprocity statistical test, the null hypothesis cannot be rejected. It can be argued that in the sample of respondents, there is no significant difference between the way of dealing with overweight and obesity depending on gender, so we do not reject $\mathrm{HO}$.

\section{Discussion}

Our goal was to identify preferred ways of dealing with overweight and obesity in the oldage patients and the elderly. The established hypothesis assumed that there would be no significant difference between the ways of dealing with overweight and obesity between men and women. For testing we used items from the questionnaire, in which the respondents had to state, in addition to gender, also the possibilities of dealing with overweight and obesity. The option of physical activity as a way of solving obesity was surprisingly chosen by a relatively large

\section{Table 1}

\begin{tabular}{|c|c|c|c|c|c|}
\hline \multicolumn{2}{|c|}{ Age, weight, height, BMI } & Age & Weight & Height & BMI \\
\hline \multicolumn{2}{|l|}{ Mean } & 64,25 & 87,93 & 169,39 & 30,49 \\
\hline \multicolumn{2}{|l|}{ Median } & 63,00 & 87,00 & 170,00 & 29,59 \\
\hline \multicolumn{2}{|l|}{ Mode } & 63 & 80 & 170 & 29 \\
\hline \multicolumn{2}{|c|}{ Standard deviation } & 7,807 & 15,509 & 7,870 & 3,935 \\
\hline \multicolumn{2}{|l|}{ Minimum } & 50 & 62 & 150 & 24 \\
\hline \multicolumn{2}{|l|}{ Maximum } & 85 & 132 & 189 & 41 \\
\hline \multirow{3}{*}{ Percentile } & 25 & 58,25 & 76,75 & 163,00 & 28,35 \\
\hline & 50 & 63,00 & 87,00 & 170,00 & 29,59 \\
\hline & 75 & 69,75 & 96,00 & 175,00 & 31,87 \\
\hline
\end{tabular}


number of respondents, $54 \%$ of men and $41 \%$ of women. In her work on similar topics, Kunesova (2005) states that while many seniors consider physical activity to be an important factor in tackling obesity, most of them do not exercise nor go for walks and spend their free time on non-physical activities, predominantly watching television and reading. Only a minimal percentage spend their free time playing sports or performing other physical activities (11). Kunesova (2016) states that physical activity is one of the most important components of obesity therapy, even in the elderly, where the goal is, among other things, to prevent or delay the onset of addiction or nonself-sufficiency of the elderly. Nevertheless, in practice, many older people are not inclined towards this option.71\% of men and $82 \%$ of women then prefer to make adjustments to their

\section{Table 2}

\begin{tabular}{|c|c|c|c|c|}
\hline & & & der & \\
\hline & & Man & Woman & responses \\
\hline Sport or other & Number & 19 & 25 & 44 \\
\hline physical activity & $\%$ according to $q 02$ & $54,3 \%$ & $41,0 \%$ & \\
\hline & Number & 25 & 50 & 75 \\
\hline & $\%$ according to $q 02$ & $71,4 \%$ & $82,0 \%$ & \\
\hline Pharmacological & Number & 2 & 9 & 11 \\
\hline loss medications & $\%$ according to $q 02$ & $5,7 \%$ & $14,8 \%$ & \\
\hline Curginal trontmont & Number & 9 & 16 & 25 \\
\hline & $\%$ according to $q 02$ & $25,7 \%$ & $26,2 \%$ & \\
\hline Not interested in dealing & Number & 2 & 6 & 8 \\
\hline with the weight gain & $\%$ according to $q 02$ & $5,7 \%$ & $9,8 \%$ & \\
\hline Total number of responde & & 35 & 61 & 96 \\
\hline Statistical significance tes & ni square & & & \\
\hline & $\begin{array}{l}\text { The value of the } \\
\text { test statistic (Chí) }\end{array}$ & & icance of & test \\
\hline $\begin{array}{l}\text { Sport or other } \\
\text { physical activity }\end{array}$ & $1,585^{\mathrm{a}}$ & & 0,287 & \\
\hline Dietadjustment & $1,445^{a}$ & & 0,305 & \\
\hline $\begin{array}{l}\text { Pharmacological way, } \\
\text { using weight loss } \\
\text { medications }\end{array}$ & $1,791^{\mathrm{a}}$ & & 0,318 & \\
\hline Surgical treatment & $0,003^{\mathrm{a}}$ & & 1,000 & \\
\hline $\begin{array}{l}\text { Not interested in dealing } \\
\text { with the weight gain }\end{array}$ & $0,495 a$ & & 0,706 & \\
\hline
\end{tabular}


diet. The high percentage of answers for this variant was again surprising, given that older people are reluctant to change established eating habits. This can also be justified by the fact that the respondents are aware that the composition of the diet and eating habits are among the basic pillars of influencing overweight and obesity treatment. Still, awareness can only be a prerequisite here, not a guarantee of change (12). Belovicova et al (2021) states that only a small part of the respondents chooses foods with reduced fat and sugar content (13). Hlubik (2007) agrees that in seniors there is still preference for foods rich in fats and simple sugars. Pharmacological treatment would only choose $5.7 \%$ of men, but up to $14.8 \%$ of women. This may be due to the fact that medications have become a phenomenon of the last century. They have saved many millions of lives, especially the most vulnerable, namely children and the elderly. Many times, however, it is more convenient to disperse the difficulty by swallowing chemicals. Unfortunately, very often, pharmacological companies support us in this approach. Most weight loss products are not very suitable for people over 65 years of age. With the possibility of surgery as a way of dealing with obesity, the percentage in both sexes was the same, 26\% (14). According to Sherman (2016), surgery can not only change patients' weight, but it can also achieve the alleviation of associated diseases. Few realize that people are more afraid of surgery than of the diseases they encounter on a daily basis. Few also realize that the risks of surgery are many times lower than the obese condition without intervention itself. Only $6 \%$ of men and, surprisingly, $10 \%$ of women in this age group do not deal with weight gain at all (15). In the monitored group of respondents, no significant difference was found between the way of dealing with overweight and obesity depending on gender, therefore we do not reject $\mathrm{HO}$.

\section{Conclusion}

Obesity is a global social problem which is not to be solved just in healthcare and it is certainly not an issue of an individual. Characteristic is the etiopathogenetic complexity of obesity, its inconspicuous and gradual course with devastating health consequences, which is secondarily difficult and expensive to treat as a separate disease. The state of knowledge on the current treat- ment options can be compared to an information vacuum, not only in lay people, but also in the medical environment of first contact. It is not just a question of overweight and obesity, it's not just the diets, but it is especially a question of our thinking and our approach to a healthy lifestyle. Although many prognoses of the future development of overweight and the complications associated with it sound very bleak, it is time for us to take an active interest in the health of ourselves and of the people around us. Addressing obesity thus requires a systematic and long-term care of many professionals. An active cooperation of the patient is also crucial. After all, no society is rich enough to afford not to treat obesity and not to solve the problem. It is therefore necessary to pay particular attention to prevention, even in the older age group, because their path to any reduction attempts is much more difficult.

\section{References}

1. FRIED M et al (2021) Interdisciplinary European Recommendations for the Surgical Treatment of Severe Obesity. Perspectives in Surgery, 2012. p. 57. ISBN 978-80-7254957-3.

2. SHEIBANI H, SABERI-KARIMIAN M, ESMAEILI $\mathrm{H}$ et al. (2020) A comparison of Body mass index and body fat percentage for predicting cardiovascular disease risk. Translational Metabolic Syndrome Research, 2020. doi: 10.1016/j.tmsr.2020.06.001.

3. SVACINA S (2008) Clinical dietetics. Praha: Grada, 2008, 384 s. ISBN 978-80-247-22566.

4. MUTAMBUDZI M, JAVED Z. (2016) Job Strain as a Risk Factor for Incident Diabetes Mellitus in Middle and Older Age U.S. Workers. The Journals of Gerontology Series B: Psychological Sciences and Social Sciences. 2016;71(6):1089-1096. doi: 10.1093/geronb/ gbw091.

5. PELIKANOVA T (2003) Diabetology and selected chapters from metabolism. 1st ed. Prague: Triton, 2003. 119 p. ISBN 978-807345-244-5.

6. LIAO Q, ZHENG Z, XIU S, CHAN P (2018) Waist circumference is a better predictor of risk for frailty than BMI in the community$d$ welling elderly in Beijing. Aging Clin Exp Res. 2018 Nov;30(11): 1319-25. 
7. NEVILL AM, METSIOS GS (2015) The need to redefine age- and gender-specific overweight and obese body mass index cut off points. Nutr Diabetes. 2015;5:el86.

8. DAVID C N et al (2017) Overweight and $a b$ dominal obesity association with all-cause and cardiovascular mortality in the elderly aged 80 and over: A cohort study. J Nutr Health Aging. 21, 597 - 603 (2017). doi:10.1007/s12603-016-0812-0.

9. REINDERS I, VISSER M, SCHAAP L (2017) Body weight and body composition in old age and their relationship with frailty. Curr. Opin. Clin. Nutr. \& Metab. Care. 20, 11 - 15 (2017). doi: 10.1097/MCO. 0000000000000332.

10. KASALICKY M (2007) Surgical treatment of obesity. Prague: Triton, 2007. 15 p. ISBN: 978-80-7254-957-3.

11. KUNESOVA M (2005) Obesity: a recommended diagnostic and treatment procedure for general practitioners. Prague: CDP-PL, 2005. 10 p. ISBN 80-903573-8-5.

12. KUNESOVA M et al. (2016) Basics of obesitology. Praha: Galen. 2016. p. 172, ISBN 978-80-7492-217-6.

13. BELOVICOVA M, POPOVICOVA $M$, VANSAC P (2021) Problems of occurrence of civilization diseases in resocialization facilities. Vyd. Slovak Society of Practical Obesity, Bardejov 2021, p. 245., ISBN: 978-80971460-8-5. EAN 9788097146085.

14. HLUBIK P (2007) Obesity in old age. Medical newspaper: Medical sheet, 2007, vol. 56, p. 8-9, ISSN 1805-2355.

15. SHERMAN MM et al (2016) Naltrexonel bupropion ER (Contrave): newly approved treatment option for chronic weight management in obese adults. Pharm Ther. 2016;41 (3):164-72. 